\title{
A COMPREHENSIVE STUDY ON HEALTHCARE LEGAL ISSUES IN ICU AND PATIENTS RECOURSE WITH RESPECT TO INDIAN LAWS
}

\author{
C.L. Avadhani, Research Scholar, (Ph. D) \\ Department of Business Administration, Annamalai University \\ Dr. G. Udayasuriyan M.B.A. M.L.S. M.Sc. M. Phil. Ph. D, \\ Professor Department of Business Administration, Annamalai University (Guide) \\ Prof. K. Viyyanna Rao M.Com., M.B.A., Ph.D., MIMA., LIII \\ Former Vice-Chancellor, Acharya Nagarjuna University (A.P.) (Co-Guide)
}

\begin{abstract}
:
The effect of Covid-19 Pandemic Globally has brought out the lacunas, more so Negligence and Malpractices of the healthcare professionals have come out. Though the stress and strain of the healthcare professionals due to work load and a sudden change in the healthcare environment are some of the causes but they are not shielded against negligence and malpractices. Covid-19 Pandemic has created an entirely new environment especially in intensive care units of any healthcare facility; Primarily due to the reasons, that maintaining physical distancing, having mask and in addition the healthcare professionals have to wear PPE (Personal Protective Equipment) Kits which are hitherto unknown to the professionals are not acclimatized are some of the causes. However, the covid patients, who are admitted into ICU are in a desperate position in breathing and they have to be provided with oxygen for survival. Since the pandemic is so severe and patients coming to the healthcare facilities for want of covid beds are more than the present capacity and the equipment in the ICU are not sufficient are also some of the causes of negligence and malpractices. This article has focused on all these issues and with reference to guidelines given by State and Central Governments from time to time and guidelines of the Apex Court, are discussed with the help of decided cases by the Highest Courts of the Country. There are also some ethical issues regarding patients and healthcare professionals and the legal recourse for the same. It is also known fact that nobody is above the law and everyone including healthcare professionals and healthcare facilities are bound by the judiciary for their wrong doings and liable for not only prosecution but also compensation to the victims (patients).
\end{abstract}

Keywords: Intensive Care Units, Healthcare, Medical Negligence, Medical Malpractice, Ethical Issues, Case Laws. 


\section{INTRODUCTION:}

The origin and establishment of Intensive Care Units in Healthcare Facilities can be linked to Flawrence Nightingale the Lady of the Lamp who left for the Crimean war in 1854 where triage was used to separate seriously wounded soldiers with non-life-threatening conditions. This separation has resulted to reduce mortality rate from $40-2 \%$ in the war field. This observation is the foundation for her later discovery of the importance of sanitary conditions in healthcare facilities, which is the critical component of the present Intensive Care Unit System. In 1950, Peter Safer an Anesthesiologist brought in the concept of advanced life support, keeping patient's sedated and ventilated in an Intensive Care Environment. That is why the safer is considered to be the father of Intensive Care Medicine, which has become a special branch of healthcare facility. In response to a polio epidemic, John Aage Ibsen, established the first Intensive Care Unit in Copenhagen in 1953. In 1955, one Mr. William Rosenthal a surgeon at the Dark Mouth - Hitchcok Medical Center started the first ICU in USA. Later on in 1960 the importance of Cardiac Arthythmias as a source of morbidity and mortality in Myocardial Infractions (Heart Attacks) was recognized and led to the routine use of Cardio Monitoring ICUs. The present healthcare facilities have various specialized ICUs that cater to a specific healthcare requirement of each patient in response to their specific want needs of that particular ailment/discomfort.

1. The importance of ICU in healthcare facility:

An Intensive Care Unit (ICU) also known as Intensive Therapy Unit (ITU) or Critical Care Unit (CCU) is a specialized Department of a hospital or healthcare facility that provides Intensive Care Medicine (Wikipedia).

The present system of healthcare in any healthcare facility is equipped with Intensive Care Unit Facilities specially designed, staffed, equipped with individual training and experience to control, monitor, operate and attend to the specific needs of each patient who are critically sick either due to ailments or injuries or both or with complications. Intensive Care Units are controlled and maintained with a defined policies, protocols and procedures, because only people having experience and qualification can only handle the equipment. The present healthcare system of multi specialty and super specialty healthcare facilities are equipped with latest technological advancements to attend the critically injured / ailments who are in critical position and needs $24 / 7$ observation. 


\section{Different Kinds of Intensive Care Units:}

According to healthcare norms, Intensive Care Units are categorized based on the pathologists / conditions treated (neurological, trauma, burns, medical or surgical ICUs) depending upon whether the patient is adult or child. There are also ICUs such as, medical, surgical, pediatric and neonatal intensive care units. All these Intensive Care Units are specific in Nature by way of equipment and personal to cater to the needs of a particular patient suffering from a particular ailment / injury.

a) Medical Intensive Care Unit: are mainly intended for the care of the adult patients with health conditions requiring 24/7 observations and treat them accordingly. Some of the ailments are, High Diabetic, Ketoacidosis, gastrointestinal bleeding, drug over dose, respiratory problems, sepsis, stroke and cancer.

b) Surgical Intensive Care Unit (SICU): All the Multi Specialty / Super Specialty Hospitals having inpatient care for critically ill who are on surgical services have to invariably posses this facility (mandatory). This Intensive Care Unit is mainly to manage post operative patients who have undergone major procedures and needs life supporting system till they come to the normalcy.

c) Pediatric Intensive Care Unit: This is a special Intensive Care Unit Facility mainly devoted for the critically ill children and just born babies with multiple complications to manage their health conditions with utmost care and observation as they cannot express themselves their problems, but only healthcare professionals have to identify and attend. This Intensive Care Unit is highly sophisticated with latest equipment such as infrared, cubical suits to keep the just born babies in a particular environmental condition.

d) Neonatal Intensive Care Unit (NICU): Though it is same as above but with a difference that this ICU is mainly responsible for the management of premature, high risk and critically ill infants of their health in addition to attend the babies with congenital disorders and birth complications.

e) Coronary Care Unit (CCU): Mainly meant for patients with severe cardiac conditions such as, myocardinal infraction or cardiac arrest.

f) Geriatric Intensive Care Unit (GICU): Mainly used for elderly persons (senior Citizens) with multiple healthcare problems that are to be attended to and with continuous monitoring. 
g) Isolation Intensive Care Unit(IICU): The importance of this Intensive Care unit has come to the floor due to Covid - 19 Pandemic. Previously this Intensive Care Unit is mainly used to the patients who are diagnosed with contagious diseases and requires isolation. The present Covid-19 Pandemic which also comes under this category requiring physical distancing medical isolation and also isolation of the healthcare professionals and paramedical staff, has gained importance.

h) Neurological Intensive Care Unit (NICU): This Intensive Care Unit is mainly meant for patients having neurological problems such as aneurysms, brain tumors, stroke, rattle snake bites and post surgical patients with various neurological surgeries requiring constant observation. Paramedical Staff/Nurses who are working in this specialized unit should posses neurological certification.

i) Physiatrist Intensive Care Unit (PICU): This Intensive Care Unit is for a specific and peculiar situation for those patients who voluntarily harm themselves.

j) Trauma Intensive Care Unit (TICU): This Intensive Care Units are provided in such healthcare facilities, that are certified in treating major trauma cases.

3. Problems faced by the patients and risks in Intensive Care Units:

It is a known fact that people will come to the healthcare facility to attend to by the healthcare professionals to their healthcare problems / ailments / discomfort and bring them to normalcy. There are known and unknown problems that may crop in during healthcare procedures by the professionals to the patients to ease their discomfort. As is said "to err is human" sometimes some unfortunate human errors like administering of wrong drug or dosage, procedure, mishandling of the professionals may occur. In addition sometimes errors committed by the healthcare professionals and paramedical staff like procedural negligence, administering of wrong dosage or drug. According Fran Griffin, PRT, NPA, Director at the Institute of Healthcare improvement in Cambridge Mass said,

"when people sometimes makes mistakes, even though the healthcare facility got a lot of well trained professionals and working very hard, still there is possibility of professionals making mistakes. Sometimes, these healthcare facility risks can be seen far beyond the control of the healthcare professionals and at times helpless." 
According to Peter B Angood, M.D., Vice President and Chief Patient Safety Officer of the Joint Commission of Oak Bridge, Terrace,

"Patients are just too passive when they check into the hospital".

Of all the errors, the most healthcare facility risk is medication error. In the words of Carolyn Clancy, M.D., Director of the Agency for healthcare research and quality (AHRQ) in Rockville, M.D., "All it takes is for someone to miss a decimal point and you could have threatening mistake. These mistakes crop in sometimes due to non availability of medication of the patients (past history) prior to joining healthcare facility." However, it is the patients duty when they are in ICU to inform immediately to the in-charge if they feel something wrong in their health condition. So that the incharge can take immediate steps to eliminate or reduce the condition.

MRSA Methicillin - Resistant - Staphylococcus - Aureus and such other healthcare facility acquired infections are also causes of healthcare conditions of the patients. These infections in healthcare facility (ICU) with bacteria or virus are a major threat of risk to the patients. These infections may occur due to surgical wounds, urinary trac infections, lung infections, blood transfusion infections, resistant to many antibiotics etc., To minimize these infections the visitors are strictly prohibited and touching the patients before washing their hands and be hygienic before entering the ICU. This is also to be observed by the attending healthcare professionals in ICU.

The other risk factor in ICU is pneumonia and though normally it is minor but at times becomes very serious and life threatening. The mortality rate due to pneumonia in ICU in developed countries is $33 \%$. This pneumonia is mainly observed in patients what having chest problems or who are on ventilators.

As already mentioned the other risk factors in ICU are due to urinary tract infections, provided to pass urine, as the patients are immobilized. The other infection normally occur is the exposure of wounds during their healing stage. If the wounds are exposed to atmosphere at the time of healing they will cause infection.

The other important ICU risk factor is deep vein thrombosis (DVT) means, development of blood clots in the Deep veins of the legs. If these blocks breaks and travels through the blood stream they will travel to the arteries of the lungs, cutting the blood's supply of oxygen and this complication can become fatal at

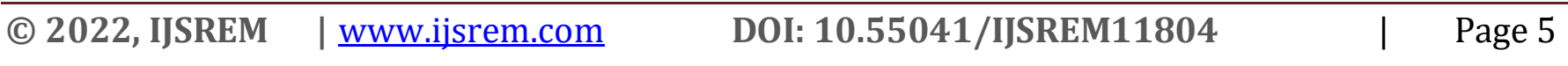


times. Major Surgeries increases the risk of DVT due to, the patient is in bed, causing bad circulation of blood and clotting the legs; also the blood clots are due to anesthesia used for surgery and till the patient comes to normalcy, the body is in a relaxed position and the blood flow will slow down and gives way for blood clots. To reduce the risk the healthcare professionals use blood thinners to reduce the risk of DVT and at the same time without increasing the risk of bleeding.

The other risks observed during procedure and when the patient is transferred to the ICU or uncontrolled bleeding after surgery which is presently minimized with the latest technology using Minimum Invasive Surgery (MIS), Laparoscopic Surgery, Robotic Surgery. All these procedures will have minimum cutting of the body or a key hole with no stitches the problems can be minimized.

In the words of Clancy, "there is no doubt that the biggest advance in improving surgical safety has been anesthesiology." However, the patient should also feel the responsibility and give full information and follow the discussions with the surgeons and anesthologists before taking a decision.

4. Human errors in healthcare facilities:

a) Action slips - selecting wrong menu when programming an infusion pump

b) Lapses - a nurse performs a structured tasks but does not use check list and, as a result, forgets an important step.

c) Mistakes - an incorrect understanding of the situation, an individual takes action that may be performed successfully but do not solve initial problem

d) Violation of Operating Practices, Procedures, Standards

e) Unfamiliarity with situation

f) Time pressure in error detection

g) Low Signal - to - noise ratio

h) Mismatch between an operators mental model and that imagined by the device designer

i) Ambiguity in performance standards

j) Disruption in normal cycle

k) Finally unreliable instrumentation

5. Nursing Errors: The service product provided by healthcare facilities, deals with human beings and their health, specific health service design is implemented and recognized all over the World. The main 
object of health services are to improve the human health and to bring them to normalcy. Though the errors in health services are common cause of concern but in Intensive Care Units where 24/7 observation is needed these human errors were become fatal at times. According to one study nursing errors are classified into 16 categories based on Rose and Rose Model. Rose and Rose model summarized them as (i) failure to perform a specific task (ii) medication errors, (iii) Performing the operation later than the dead line, (iv) carrying the activity in wrong direction, (v) not performing the task excessive long term performance visits, steps not performed, (vi) step visits done on the wrong case, (vii) information received or sent incorrectly, (viii) incorrect action is performed on the right case, (ix) proper action is performed on the wrong case, (x) failure to visit the deadline, are some of the nursing errors in ICU. In addition misuse of equipment by nurses in ICU is alarming, because, inexperienced and in sufficiently qualified nurses posted in the ICU are some of the main reasons. Equipment failures on important occasions, nurses not following the dictum of the manufacturer, lack of maintenance, lack of availability of certain parts, interruption of electrical supply during procedures have alarming effect on the patient's condition. In addition behaviour of the nurses and the attitude towards work may be due to stress, strain and personal matter influencing are some of the causes. In covid-19 pandemic environment, since the patients are admitted in the ICU and are on ventilators and are life supporting system, any interruption by the nurses who are attending or electrical supply breakdowns will be fatal on some occasions. As an example, Hallet Hospital in Kanpur, Five patients died in ICU following failure of AC Plant.

\section{Malpractices/Diagnostic Errors in ICU in Healthcare facilities in general:}

Normally, the patients who are admitted in ICU or in a critical position and fighting for the life, any procedural failure by the healthcare professionals or diagnostic errors due to inefficiency in diagnosing the real cause of ailment by the healthcare professional will come under malpractice. A study conducted in this regard found that,

"Diagnostic errors are clinically and financially costly today than ever before. Efforts to identify, monitor and reduce the rates of such errors, therefore greater attention and more dedicated resources and they are received in the past."

NAM defines Diagnostic Errors as,

"the failure to (a) establish an accurate and timely explanation of the patient's health problems, (b) communicate that explanation to the patient." 
There are six different types of diagnostic errors categorized:

(i) Missed Diagnosis: When a diagnostic tests do not provide an explanation for a patient's complaints (common in patients with chronic fatigue or chronic pain)

(ii) Wrong Diagnosis: When the original diagnosis is found to be incorrect because the true cause is discovered later (patient having heart attack the pain is from acid indigestion)

(iii) Delayed Diagnosis: the most common type of diagnostic error in which the Diagnosis should made earlier

(iv) Failure to recognize the complication

(v) Failure to diagnose the related disease: The Doctor correctly diagnosis one disease but fails to diagnose a related disease. A related disease is one that often goes hand - in - hand with primary condition or that has higher risk of incidence in patients with primary disease.

(vi) Failure to diagnose an unrelated disease: the Doctor correctly diagnosis one disease but fails to diagnose a completely unrelated second disease.

An observation made by researchers found that incidence of misdiagnosis is very high in ICUs and the reason being increased pressure of time and makes the professionals unable to take decisions in split second.

\section{Medical Negligence in Intensive Care Units:}

The characteristics of the medical negligence is failure to exercise due care and diligence. The three main ingredients required to prove medical negligence in a court of law are, (i) The defendant (healthcare professional) owes a duty of care towards the patient (complainant); (ii) There is a breach of this duty to the defendant; (iii) due to this breach by the defendant the plaintiff suffered injury; that means, wrongful actions or omissions of healthcare professionals in healthcare delivery system in the persuit of their profession while dealing with the ailments / discomforts of the patients. The term Medical Negligence has not been defined in any of the statues are enacted in Indian Laws. However,

(a) The Apex Court (2004) 6 SCC 422 held by the bench that, in order to fasion criminal liability "the medical negligence should be gross or reckless. A person cannot be held criminally liable for mere lack of necessary care or attention or skill. However a want of certain degree of care might create a civil liability." 
(b) The Apex Court in another Judgment in Poonam Varma Vs. Ashwin Patel and Ors., the court held that, "Negligence has many manifestations - it may be active negligence, collateral negligence, comparative negligence, concurrent negligence, continued negligence, criminal negligence, gross negligence, hazardous negligence, active and passive negligence, willful or reckless negligence or negligence per se."

(c) Negligence Per Se: "Conduct, whether of action or omission which may be declared and treated has negligence without any argument or proof as to the particular surrounding circumstances, either because it is in violation of a statue or valid municipal ordinance or because it is so palpably opposed to the dictates of a common credence it can be said without hesitation or doubt that no careful person would have been guilty of it. As a general rule the violation of a public duty, enjoyed by law for the protection of person or property, so constitutes."

(d) The Apex Court in Balachandra Bapu and Anr. Vs. State of Maharashtra opined that. "while negligence is an omission do something which a reasonable man guided upon those consideration which ordinarily regulate the conduct of human affairs, would do, or doing something which a prudent and reasonable man would not do; criminal negligence is the gross and culpable neglect or failure to exercise that reasonable and proper care and precaution to guard against injury either to the public generally to an individual which having regard to all the circumstances out of which the charge has arisen it was the imperative duty of the accused of the person to have adopted"

(e) Jacob Mathew v. State of Punjab \& Another- In this case, the Supreme Court while dealing with the case of negligence by professionals also gave illustration of medical and legal profession and observed as under:

"In the law of negligence, professionals such as lawyers, doctors, architects and others are included in the category of persons professing some special skill or skilled persons generally. Any task which is required to be performed with a special skill would generally be admitted or undertaken to be performed only if the person possesses the requisite skill for performing that task. Any reasonable man entering into a profession which requires a particular level of learning to be called a professional of that branch, impliedly assures the person dealing with him that the skill which he professes to possess shall be exercised and exercised with reasonable degree of care and caution. He does not assure his client of the result. A lawyer does not tell his client that the client shall win the case in all circumstances. A physician would not assure the patient of full recovery in every case. A surgeon cannot and does not guarantee that the result of surgery 
would invariably be beneficial, much less to the extent of $100 \%$ for the person operated on. The only assurance which such a professional can give or can be understood to have given by implication is that he is possessed of the requisite skill in that branch of profession which he is practicing and while undertaking the performance of the task entrusted to him he would be exercising his skill with reasonable competence. This is all what the person approaching the professional can expect. Judged by this standard, a professional may be held liable for negligence on one of two findings: either he was not possessed of the requisite skill which he professed to have possessed, or, he did not exercise, with reasonable competence in the given case, the skill which he did possess. The standard to be applied for judging, whether the person charged has been negligent or not, would be that of an ordinary competent person exercising ordinary skill in that profession. It is not necessary for every professional to possess the highest level of expertise in that branch which he practices.

\section{(f) Medical Negligence under Section 304A of IPC}

The Apex Court while dealing with Sec. 304 A of IPC (death caused by Negligence) cited the following,

"To impose criminal liability under Section 304A of Indian Penal Code, it is necessary that the death should have been the direct result of a rash and negligent act of the accused, and that act must be the proximate and efficient cause without the intervention of another's negligence. It must be the causa causans; it is not enough that it may have been the causa sine qua non."

(g) In Mohan Vs. Prabhaji Nair and another (2004) CPJ 21 (SC) (10) of 2004 February 04, the Apex Court, ruled that,

“a Doctor's negligence could be ascertained only by scanning the material and expert evidence during a trial. In Suresh Gupta's case, in August 2004, the Apex Court said "standard of negligence that had to be proved to fix a Doctor's or Surgeon's criminal liability, was set-at "gross negligence" or "recklessness". Also the Apex Court distinguished between error of Judgment and culpable negligence. It also held that criminal prosecution of medical personnel without sufficient medical opinion, pointing to their guilt, would do great harm to the medical community. A Doctor cannot be tried for culpable or criminal negligence in all cases of medical misfortunes. However, the liability of a Doctor/Surgeon medical negligence in civil cases if proved, the patient can get compensation as decided by the Court. However, mere carelessness or due attention and skill cannot be described as so wreckless or grossly negligent as to make her/him 
criminally liable. The Courts also held that this distinction was necessary for the medical professionals being exposed to civil liability in addition risk of imprisonment for medical negligence".

\section{Medico Legal Cases with respect to Indian Laws:}

It is most relevant to mention the noble words of Hon'ble Chief Justice of India, Hon'ble CJ N.V. Ramana while addressing the gathering organized by Karnataka State Bar Council to pay tributes to Late Mr. Justice Mohan M. Santhanagowda, I quote, "the need of the hour is the Indianization of our legal system. When I say Indianization I mean the need to adapt to the practical realities of our society and localize our justice delivery system." Their Lordship also mentioned that, "courts need to be litigant centric, as they are the ultimate beneficiaries. The simplication of justice delivery should be our pressing concern. It is crucial to make justice delivery more transparent, accessible and effective. Procedural barriers often undermine access to justice. The common man should not be apprehensive about approaching the courts and authorities. While approaching the court, he should feel the scared of the judges and courts. He should be able to speak the truth."

1) Doctor Patient Relationship: To proceed against any healthcare professional for deficiency in service the complainant should prove that there exists a relationship between the patient and healthcare professional and that the patient is under the care and medication of the healthcare professional by paying requisite some of money

2) According to Indian Laws, the following legal provisions will apply to make a complaint against healthcare professional by the sufferror (patient) under Medical Negligence / Malpractices.

a) Fundamental Rights, under Art. 21 and Art. 32 of the Indian Constitution

b) Directive Principles of State Policy under Articles 41, 42 and 47

c) Indian Penal Code (IPC), the sections that attracts are Secs, 52, 80, 82, 88, 90, 92, 304A and 337

d) Under tort

e) According to Indian Laws, Medical Negligence or Malpractice can be categorized into Criminal Negligence, Civil Negligence, Negligence under Consumer Act

3) Consumer Protection Act: The landmark Judgments by the Apex Court in Indian Medical Association Vs. V.P. Santha and Ors., the three Judge Bench held that "Service rendered to a patient by a medical practitioner by way of consultation, diagnosis and treatment, both medical and surgical, would fall within the ambit of services as defined in section 2 (1) (o) of the Consumer Protection Act, 1986." 
While deciding whether the complaint comes under consumer act or not, the Apex Court made the following observation,

"In the matter of professional liability professions differ from occupations for the reason that professions operate in spheres where success cannot be achieved in every case and very often success or failure depends upon factors beyond the professional man's control. In devising a rational approach to professional liability which must provide proper protection to the consumer while allowing for the factors mentioned above, the approach of the Courts is to require that professional men should possess a certain minimum degree of competence and that they should exercise reasonable care in the discharge of their duties. In general, a professional man owes to his client a duty in tort as well as in contract to exercise reasonable care in giving advice or performing services."

4) National Consumer Redressal Commission (NCRDC): To establish Medical Negligence, the NCRDC said, "sympathy cannot substitute for conclusive evidence of medical negligence."

The NCRDC passed an order in Shrishti Puri Vs. AIMS observed that, "It is not uncommon that while putting the rod into a corrective position, at times, the screws moves slightly from the original position which can cause neurological or vascular problems in few patients." Therefore the commission could not find the case of medical negligence and stated that the spinal correction surgery took place as per the accepted standards and referred to the Supreme Court Decision in Atchyuta Rao Harbhavu Khodva Vs. State of Maharashtra 1996 (2) SC 634., while adding that the Bench has sympathy for the patient for having congenital kyphoscoliosis deformity, however, "sympathy cannot substitute for conclusive evidence of Medical Negligence".

9. Rights of Patients to proceed against healthcare providers, healthcare facilities and Professionals:

1) Compensatory action against healthcare professionals, providers and staff before civil court under the law of torts or law of contract, High Courts, Consumer Courts to initiate action against the guilt.

2) Disciplinary action against healthcare professionals, hospitals before the statutory bodies governing medical practitioners (Indian Medical Council or State Council)

3) Vicarious Liability against the professionals and providers who are not directly involved in the Negligence of the Professionals / Providers.

10. Remedies available to the patient in an Intensive Care Unit for Negligent Act and Malpractices: 
1) Suit for damages under Civil Procedure Code

2) Complaint for Negligence under Criminal Procedure Code

3) Compensation and Redressal under Consumer Protection Act

4) Disciplinary Action against erring healthcare professionals by Indian Medical Association or State Councils and at times cancellation or suspension of registration depending upon the nature of Negligence.

5) Protection of life and personal liberty guaranteed by Indian Constitution under Art. 21

6) Criminal Complaints against healthcare professionals under Sections 304 A, 336, 337 and 338 of IPC for Medical Negligence loss of life and injury to the patient

7) However, Sec. 80 of the IPC clearly says that "anything which happens as a result of an accident or misfortune and without any criminal intention or knowledge in the doing of a lawful act in a lawful manner by lawful means and with proper care and caution is not an offence"

8) Sec. 81 of the IPC protects healthcare professional, "if anything is done merely by the reason that it is likely the reason cause but the same is done without any intention to cause harm and in good faith in order to cause other damages to person or property", is not an offence.

9) Sec. 88 of the IPC clarifies that, "No one can be made an accused of any offence if he/she performs an act in good faith for the good of the other people does not intend to cause harm even if there is a risk involved and the patient has given the consent explicitly or implicitly."

\section{Consent and maintenance of health records and the legal importance:}

Consent: It is mandatory for any healthcare professional to have a written consent if the patient is in a position to do so, before proceeding do any surgery. In case, if the patient is not in a position either to understand or give his consent the legal representative of the patient has to give consent in writing accepting the procedure to be performed on the patient. This is mandatory because any misfortune if occurs to claim by the either of the party consent is required. If no consent the healthcare professional is liable for all the costs and consequences arising there from, if there is any problem in the procedure. In this regard the Apex Court in the case of Sameera Kohli Vs. Dr. Manichanda a summarized the principles

(a) A Doctor has to seek and secure the consent of the patient before commencing a treatment / procedure. The consent so obtained should be real and valid, which means that the patient should have the capacity and competence to consent; His/Her consent should be voluntary and should be based on the basis of 
adequate information concerning the nature of ailment, treatment procedure, so that he /she what is consenting to.

(b) The adequate information to be furnished by a Doctor or a [member of his / her team], who treats the patient should enable the patient to make a balanced judgment as to whether he / he should submit himself / herself to the particular treatment or not; that means the Doctor should disclose

(c) In Healthcare practice, essential pre requisite for the commencement of a procedure to a patient is to get consent from the patient or the guardian. Without consent the procedure amounts to trespass and battery on patient's health. An adult who attained the age of 18 and of sound mind has the right to give or refuse consent to healthcare procedure or treatment even if that refusal may result in the death of that patient. The medical Council of India's, guidelines mention

“...must make sure that patients have given their consent before you provide any medical Investigation, examination or treatment. Consent is required by law and is an essential part of respect for patient's, autonomy. Patients have the right to decide what happens to the own body."

The consent can be expressed [given verbally or in writing] or it can be implied [where the patient's specific behaviour implies that they have consented to a particular procedure]. Regarding written consent, apart from in situations where this is required by statue. Firstly, there is no general legal mandate requiring consent to be in writing [although many practitioners some times incorrectly assume otherwise] and Secondly, there is no longer place in the practice of modern medicine for the stubborn insistence and rational of consent form being the "be all and end all" in relation to consent. The validity of a consent does not depend on the form which it is given, it is vital that any consent given is a valid consent. If a patient gives consent to a healthcare procedure but has not been given any information in relation to the procedure, or is clearly not able to understand anything that has been explained, the informed consent to that procedure will not be valid. Also, "consent is not valid if the patient has not been given enough information to make a decision."

In order to be a consent is valid the necessary ingredients are,

a. Given by a person with capacity, and

b. Voluntarily given without any element of duress, and 
c. With requisite information of risks, side effects and alternatives such that patient is able to make an informed decision as to whether or not to proceed with procedure.

The HSC National Consent Policy states that,

"Those who provide health and social care services must work on the presumption that every adult service user has a capacity to make decisions about their care and to decide whether to agree to or refuse, an examination, investigation or treatment."

The British Medical Association [BMA] States that,

"to demonstrate capacity individuals should be able to:

Understand [with use of communication aids, if appropriate] in simple language what the medical treatment is, its purpose and nature and why it is being proposed.

Understand its principal benefits, risks and alternatives

Understand in brought terms what will be the consequences of not receiving the proposed treatment

Retain the information for long enough to use it and weight it in the balance in order to arrive at a decision Communicate the decision [by any means]"

(d) Alternative if any available,

An outline of substantial risks and

Adverse Consequences of Refusing Treatment / Procedure

(e) Consent given only for diagnostic procedure cannot be considered as consent for the therapeutic treatment. Consent given for a specific treatment procedure will not be valid for conducting some other treamtent procedure. The fact that unauthorized additional surgery is beneficial to the patient or that it would save considerable time and expense to the patient or would relieve the patient from pain and suffering in future, are not grounds of defense. The only expectation to this rule is whether the additional procedure though unauthorized, is necessary in order to save the life.

\section{Health Records:}

Health Records are the backbone of healthcare of a patient and are valuable information for the present, future of the patient as well as scientific community. In additional health records plays an important role in 
legal frame work when something goes wrong, the patient or the accomplice, on the basis of the health records can claim for criminal, civil and consumer relief on the erring healthcare professionals and at the same time the healthcare records will become a shield for the healthcare professionals to prove their innocence. Healthcare records are the documentary evidence in legal claims. Though there is no strict rule of preserving the health record of a patient but the health records should be preserved for a period of three years, that is the limitation period in accordance with the Indian Laws. In addition it is mandatory on the part of the healthcare facilities / providers to keep the records in privacy and should not be made public without the written consent of the record holder.

Indian Laws that attracts health records including EHR:

There are many provisions in the Indian legal system under different sections regarding patients rights, in claiming under civil criminal and consumer acts

a) The constitution of India Art, 21

b) Indian Medical Council (Professional Conduct and Etiquity and Ethics) Regulations, 2002

c) The Consumer Protection Act, 1986

d) Drugs and Cosmetic Act, 1980

e) Clinical Establishment Act, 2010

f) CPC, CRPC, Evidence Act and Contract Act (Certain Applicable Sections)

g) Rights of the Patients

(a) Right to Information

(b) Right to Informal Consent

(c) Right to Confidentiality and Human Dignity and Privacy

(d) Right to be heard and Seek Redressal

(e) Protecting Data, Privacy of Patient's and Privacy Laws in India

The Apex Court in K.S. Puttu Swamy Vs. Union of India, 2017 observed, "previously, not considered a fundamental right under the Indian Constitution; However, the Indian Judiciary at present carved out a distinctive zone regarding privacy and an upshot i.e., Right to Privacy, it is now recognized as a fundamental right under Art. 21 of the Indian Constitution." Only after passing of this Judgment by the Apex Court, Right to privacy is given to recognition and it is not only conceded nationality, but also Internationally under various conventions. 
The Indian Legal system during controversaries in Medical Negligence and Medical Malpractice cases relays mainly upon the documentary evidence in a situation where negligence of healthcare professionals is alleged either by the patient or their accomplice and this health records will become most important evidence in deciding the charges, paying compensation or acquittal of the healthcare professionals. "Poor Records mean poor defence and no record means no defence." Normally health records include variety of documentation of the patient's history, clinical findings, diagnostic test results, preoperative care, operation notes, post operative care and notes regarding daily progress of the patient and the medication.

\section{Medical Council of India issued guidelines on Medical Records:}

The following guidelines are issued under MCI Regulations 2002.

1) Maintain indoor records in a standard proforma and preserve them for three years from the commencement of treatment (Sec. 1.3.1) and Appendix - 3.

2) Request for Medical Records by patient or any authorized person should be acknowledged and documents issued within $72 \mathrm{Hrs}$ (Secs. 1.3.2)

3) Maintain a Register of Certificates with the full details of Medical Certificates issued with atleast one identification of the patient and his / her signature (Sec. 1.3.3)

According to Indian Laws under the provisions of Limitation Act, 1963 and Sec. 24 (a) Consumer Protection Act, 1986 defines a time which a complaint has to be filed. Accordingly it is advisable to the healthcare providers and facilities to maintain health records for two years of outpatient and three years of inpatient. This Limitation aspect of filing a case in a consumer court of law, it is under the direction of the judiciary in medical negligence and malpractice cases to waive the delay.

In case of a pediatric case, the child is entitled to claim compensation after attaining the age of majority. It is mandatory on the part of the healthcare providers and facilities that all the healthcare records that are subject to medico legal cases should be maintained until the subject matter comes to finality.

The provisions of certain special Acts like, (i) the preconception, prenatal diagnostic test Act, 1994 (PNDT), (ii) Environmental Protection Act, etc., necessitates proper maintenance and retention of health records for periods as specified in Sec. 29 of the PNDT Act. However, all the health records are to be kept in tact till the cases reaches their finality in the highest court of the land. In addition the health records should be in the case custody of the healthcare providers and they should be in a position to produce them before any judicial body on demand because as per the Sec. 3 of the Evidence Act, 1872 (amended in 
1961), health records are main evidence. Any mishandling of the records, entries made after the discharge of the patient, erasing certain entries are all disallowed as an evidence in the court.

Health records are usually summoned by the Judiciary in the following cases

1) Criminal Cases for providing the nature, timing and gravity of the injuries, because it acts as corroborative evidence in case of death of a patient

2) In Road Accident cases under MACT Act, to decide the amount of compensation to be paid to the diseased.

3) Labour Courts in relation to workmen compensation act.

4) For Insurance Claims to prove the duration of illness and the cause of death.

5) In one Consumer Case, the State Commission held that failure to deliver $X$ ray films and such other health records pertaining to a patient is deficiency in service when demanded by patient or by authorized patient. The patient can claim compensation.

6) In another important case Bombay High Court held that when a patient or the authorized agent demanded healthcare records of the patient the healthcare providers cannot deny the same on the basis of confidentiality but are duty bound to supply the entire records under Medical Council of India, 2002.

\section{Ethical Issues on Covid - 19 Triage:}

Covid-19 Pandemic has brought into focus many healthcare ethical questions such as, a burden on Intensive Care Unit physicians and other paramedical staff working in ICU.

After lot of deliberations and discussions by International Bodies connected with health and healthcare have come to some recommendations regarding Ethical Guidelines on Covid-19

1) Respect for the patients will

2) Fair Distribution and Maximization of benefits based on chance of survival are at the heart of the recently issued triaging guidelines

3) Long term considerations

4) Life expectancy

5) Combination with quality of life 
These guidelines are provided to reduce the burden on those who need to determine, which patient gets access to a scarce resources. To the extent that it is unavoidable that the physicians, have to decide who must die and whom they shall keep alive. There should not be any lottery system or first come first served approach.

The American Medical Association Reaffirmed their stance, "it is a responsibility of health professionals to continue caring for patients even if doing so presents some danger to them." This includes an "obligation to provide urgent medical care during disasters..... even in the case of greater than usual risks to 'physicians' own safety, health or life." Unfortunately 100s of healthcare profeissonals lost their life since the pandemic began in serving the needy. The main problem in any country in any healthcare facility is limited number of critical care resources such as, ventilators, intensive care unit beds, supply of oxygen and uninterrupted continuous power supply.

Conclusion: The Apex Court while awarding 76 Lakhs as compensation to the complainant observed that, "The grant of compensation to remedy the wrong of medical negligence is within the realm of law of torts. It is based on the principle of restitution in integrum. The said principle provides that a person is entitled to damages which should as early as possible get that sum of money which would put till in the same position as would have been if he had not sustained the wrong."

As already mentioned above, Covid-19 Pandemic world over has brought catastrophe not only in healthcare sector but all other areas including the livelihood of the down tradon and the under privileged heavily. Many countries suffered economically, financially due to strict implementation of physical distancing and wearing a mask in the public to minimize the pandemic. However, the threat is not still over as people are expecting the third wave and multiple variants by changing the Covid-19 into different shapes and causing different health problems. Hence, in this article the author made an emphasis on healthcare due to covid-19 Pandemic with reference to Intensive Care Units and the legal relief to the victims according to Indian Laws and Acts. The subject is too wide and the author made an emphasis on main ingredients to get a better picture of the effect of Covid-19 on health and healthcare and the legal system with respect to Indian Laws.

Mahatma Gandhi the father of the Nation said,

"Health is wealth, but not piece of Gold and Silver" 


\section{References:}

1. Poonam Verma v. Ashwin Patel \& Ors. - SCC

2. Black's Law Dictionary

3. Bhalchandra @ Bapu \& Another v. State of Maharashtra - SCC

4. Jacob Mathew v. State o Lakhs f Punjab \& Another - SCC

5. Achutrao Haribhau Khodwa \& Others v. State of Maharashtra \& Others - SCC

6. C.P. Sreekumar (Dr.), MS (Ortho) v. S. Ramanujam - SCC

7. Kurban Hussein Mohammedali Rangawalla v. State of Maharashtra - SCC

8. Sir Lawrence Jenkins in Emperor v. Omkar Rampratap

9. Indian Medical Association Vs.. V.P. Shantha \& Others - SCC

10. Mohan Vs. Prabhaji Nair and another (2004) CPJ 21 (SC)

11. Hampton Vs State: State Vs Lester

12. Shivaram Vs the State, AIR 1965, All 196

13. Martin D Souza Vs Mohammad Isfaq (2009) 2 SCC 40

14. Vijay Sinha Roy (D) by LR Vs. Biswanath Das

15. (Anuradha Saha Vs. AMRI Hospital)

16 V.N. Shrikhande vs Anita Sena Fernandes [(2011) 1 SCC 5

17. Bombai Mirror, Nov.22, 2016)

18. Jaipur Golden Hospital, Rohini, Delhi. (India Times)

19. Bhatra Hospital and Medical Research Center and others Vs. Kusum Sharma and others.

20. Vinod Jain Vs. Santokpa Durlabji Memorial Hospital and Others

21. Dr. Lakshman Balakrishna Joshi vs. Dr. Trayambak Babu Godbole

22. Chandigarh Clinical Laboratory Vs. Jagjeet Kaur (NCDRC)

23. Calcutta Medical Research Institute vs. Bimalesh Chaterjee

24. Jasbi kaur Vs. State of Punjab

25. M. Ramesh Reddy Vs. State of Andhra Pradesh (1975 36 STC 439 AP)

26. State of Haryana Vs. Smt. Santra

27. Dr. M. Kochar Vs. Ispita Seal (NCDRC)

28. V. Krishna Rao Vs. Nikhil Super Specialty Hospital

29. AS Mittal and Anr. Vs. State of U.P. \& Ors., (Art. 32 of the Constitution) (1989 AIR 1570)

30. Balachandra @ Babu and Anr. Vs. State of Maharashtra (1968 SCR (3) Page 766)

31. Spring Medows Hospital and Anr. Vs. Harjol Ahuwalia 
32. Martin F. D' Souza vs Mohd. Ishfaq 2009 (3) SC 1, necessity of medical opinion was observed to be mandatory even for civil cases which requirement was subsequently observed to be per incuriam in V. Krishna Rao Vs Nikhil Super Specialty Hospital (2010 (5) SCC 513)

33. Civil Appeal Nos. 227-228/2019, Arun Kumar Manglik Vs. Chirayu Health and Medicare Private Limited and Anr. (SC)

34. Latha Wadva and National Insurance Company Ltd., Vs. Pranay Sethi 